\title{
Reply to "Global coastal wetland expansion under accelerated sea-level rise is unlikely"
}

[This article is a non-peer reviewed preprint submitted to EarthArXiv. It is a reply to Törnqvist et al., published on EarthArXiv in July 2019 (DOI:10.31223/osf.io/d2nhs).]

Mark Schuerch ${ }^{1 *}$, Tom Spencer ${ }^{2}$, Stijn Temmerman ${ }^{3}$, Matthew L. Kirwan ${ }^{4}$, Claudia Wolff ${ }^{5}$, Daniel Lincke $^{6}$, Chris J. McOwen ${ }^{7}$, Mark D. Pickering ${ }^{8}$, Ruth Reef ${ }^{9}$, Athanasios T. Vafeidis ${ }^{5}$, Jochen Hinkel ${ }^{6,10}$, Robert J. Nicholls ${ }^{11}$, Sally Brown ${ }^{12}$

1 Lincoln Centre for Water and Planetary Health, School of Geography, University of Lincoln, Lincoln, United Kingdom

2 Cambridge Coastal Research Unit, Department of Geography, University of Cambridge, Cambridge, United Kingdom

3 Ecosystem Management Research Group, University of Antwerp, Antwerp, Belgium

4 Virginia Institute of Marine Science, College of William and Mary, Gloucester Point, Virginia, USA

5 Institute of Geography, Christian-Albrechts University of Kiel, Kiel, Germany

6 Global Climate Forum, Berlin, Germany

7 UN Environment World Conservation Monitoring Centre, Cambridge, United Kingdom

8 Ocean and Earth Science, National Oceanography Centre, University of Southampton, Southampton, United Kingdom

9 School of Earth, Atmosphere and Environment, Monash University, Clayton, Victoria, Australia

10 Division of Resource Economics, Thaer-Institute and Berlin Workshop in Institutional Analysis of SocialEcological Systems (WINS), Humboldt-University, Berlin, Germany

11 Tyndall Centre for Climate Change Research, University of East Anglia, Norwich, United Kingdom

12 Department of Life and Environmental Sciences, Bournemouth University, Poole, United Kingdom

*Corresponding author: mschuerch@lincoln.ac.uk

We thank Törnqvist et al. for engaging with our modelling study on the future response of global coastal wetlands to sea-level rise (SLR) ${ }^{1}$ and their careful and critical discussion of the presented methods and results. However, we disagree with their suggestion that our modelling approach is inadequate, a claim which relies on two arguments: (1) they argue that our results are inconsistent with the "A/S (accommodation versus sediment supply) theory"; (2) they refer to coastal Louisiana as a case example where our modelling results would deviate from historic observations ${ }^{2}$ and future projections ${ }^{3}$ of coastal wetland change. However, below we will demonstrate that Törnqvist et al.'s application of the A/S theory is not valid to predict changes in coastal wetland area, and that our global predictions are in line with regional observations and projections for coastal Louisiana and the wider region of the Gulf of Mexico.

Taking coastal Louisiana as an example, Törnqvist et al. highlight that ca. $6000 \mathrm{~km}^{2}$ of land are expected to be lost over the coming 50 years ${ }^{3}$ due to RSLR and the erosion/drowning of coastal wetlands. However, this figure cannot directly be compared to our results, because it does not account for upland areas being converted to wetlands as sea level rises; it only accounts for seaward losses due to erosion and/or drowning with associated shoreline retreat and land loss ${ }^{3}$. Equivalent scenario runs of our model (i.e. only considering wetland accretion, but no inland migration) result in a comparable projected wetland loss in Louisiana of ca. $6,900 \mathrm{~km}^{2}$ until 2100 , under the medium SLR scenario (RCP4.5). This loss is triggered by insufficient sediment availability for the marshes to keep pace with SLR in situ ${ }^{2,4}$. Hence, Törnqvist et al.'s claim that our model underestimates future wetland loss on the US Gulf coast is incorrect. Rather, we demonstrate that our global-scale model predictions of wetland losses are comparable to regional estimates.

Furthermore, recent field evidence ${ }^{5}$ and modelling studies ${ }^{6}$ highlight that wetland inland migration in response to SLR will be very likely along the entire US Gulf coast, and will happen primarily as a function of coastal topography and SLR, where anthropogenic barriers are absent ${ }^{6,7}$. Observations/modelling 
elsewhere suggest that marsh migration into retreating uplands is regionally important for marsh survival $^{8,9}$, and that these gains may well exceed seaward losses ${ }^{5,8,10}$. On the US Gulf coast, for a $1.2 \mathrm{~m} \mathrm{SLR,}$ Enwright et al. ${ }^{6}$ identify an area of ca. $19,600 \mathrm{~km}^{2}$ where coastal wetlands are likely to migrate into (excluding ca. 4,000 $\mathrm{km}^{2}$ where migration is inhibited by urban land and levees). In comparison, the corresponding area in our model (for RCP8.5 SLR scenario and assuming no barriers to inland migration) is ca. $11,000 \mathrm{~km}^{2}$, hence lower, but of the same order of magnitude as Enwright et al. ${ }^{6}$. Therefore, we may conclude that our global model is also consistent with regional mapping projections. Both approaches illustrate that the area of potential marsh migration is comparable to the area of current wetland extent on the US Gulf coast of $13,600 \mathrm{~km}^{2 ; 11}$. Hence this adaptation mechanism cannot be neglected.

Inland migration of coastal wetlands is driven by the conversion of terrestrial vegetation to coastal wetlands, a process that occurs on time scales of a few years only ${ }^{12}$ and is primarily controlled by hydrological factors (inundation frequency, salinity, etc.). Unlike interpreted by Törnqvist et al. ("the basic tenet of the Schuerch et al. model is that the accommodation created by RSLR is generally filled with sediment"), we do not assume that complete sediment infilling of accommodation space is necessary for vegetation conversion. Rather, we reject Törnqvist et al.'s $\mathrm{A} / \mathrm{S}$ model for coastal wetland modelling, as it assumes that complete sediment infilling is needed for vegetation conversion. This neglects that wetlands exist within an elevation range and assumes that all wetlands are at a single elevation above MSL with a flat marsh surface (Fig. 1a), clearly an unrealistic assumption ${ }^{13}$.

As coastal wetlands occur within a reasonably large elevation range (our model assumes elevations between mean sea level (MSL) and mean high water spring (MHWS)), coastal wetlands established through the conversion of terrestrial vegetation will survive at least as long as it takes for local sea levels to rise by MHWS-MSL $(\mathrm{m})$. In other words, wetlands that are newly created through inland migration may survive, even when the available accommodation space created by RSLR is not completely filled by sediments (Fig. 1b). This concept of increased resilience of wetlands located high within the tidal frame may be referred to as "elevation capital"13. A back-of-envelope-calculation on the expected lifetime of tidal wetlands to persist in the case of no sediment supply and an assumed MHWS level of $1 \mathrm{~m}$ above MSL (which, according to our data, is the global median MHWS where wetlands are present), combined with a RSLR rate of $10 \mathrm{~mm} \mathrm{yr}^{-1}$, shows that wetlands would still survive for at least 100 years, thereby exceeding our model simulation period. Assumes no sediment input/vertical accretion at all, this clearly underestimates the wetland's lifetime. 
a) Törnqvist example, complete infilling of accommodation space

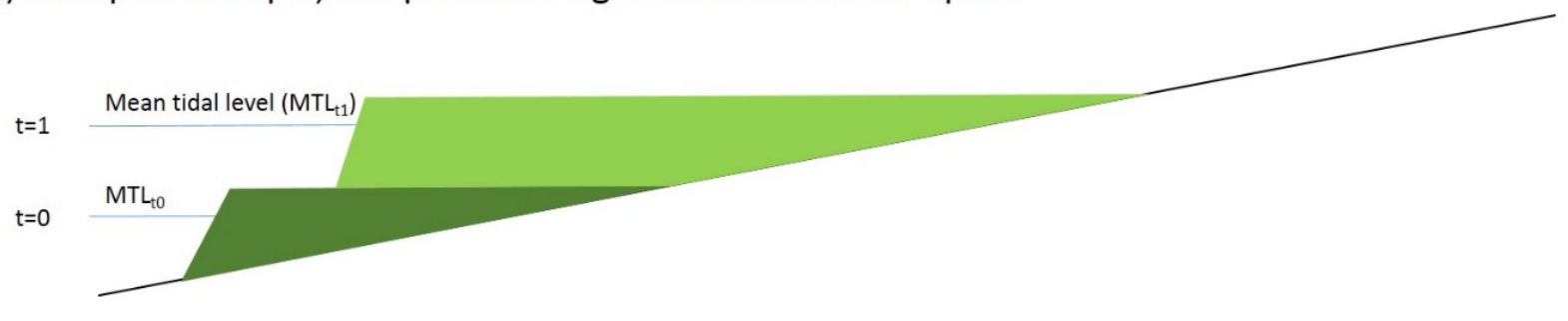

b) Our example, incomplete infilling of accommodation space

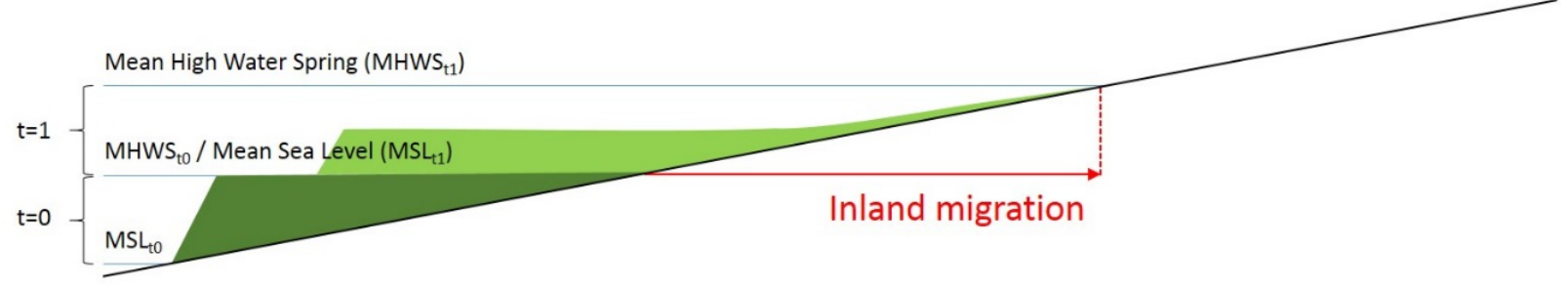

c) Our example, incomplete infilling of accommodation space + topographic variations

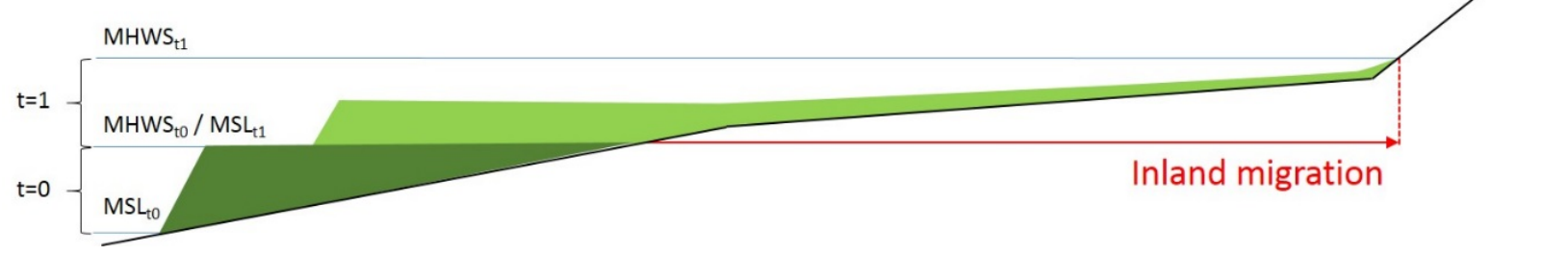

Figure 1: Classical A/S theory vs. our modelling approach ${ }^{1}$. a) A/S theory as presented by Törnqvist et al., where wetland migration requires vertical accretion $\geq S L R$, hence wetland surface is flat (around some mean tidal level); $b$ ) Wetland migration, as represented in Schuerch et al. ${ }^{1}$, if accommodation space in not fully infilled, but inland migration occurs as wetlands exist within an elevation range; c) Marsh migration, as represented in Schuerch et al. ${ }^{1}$, if accommodation space in not fully infilled, and wetland extent increases due to inland migration and topographic change.

The newly created wetlands, where sediment supply is low, would tend to move inland with time, a process that is associated with shoreline retreat and wetland loss at the seaward side, as observed in coastal Louisiana for example $e^{2,3}$. The future wetland extent would primarily be a function of SLR and coastal slope (i.e. where slopes increase at the landward edge of the wetland, wetland areas would decrease; where slopes decrease, wetland areas would increase ${ }^{7,10}$ (Fig. 1C)). Dramatic losses would only occur where wetland inland migration was inhibited by natural or human barriers ${ }^{6,10}$.

Where wetland area increases via inland migration, Törnqvist et al. rightly highlight that, based on the A/S ratio $^{14}$, the sediment volumes needed for wetlands to keep pace with SLR (i.e. available accommodation space is completely filled) will increase. However, as described above and in Fig. 1, this is no pre-requisite for inland migration due to the wetland's elevation capital at its landward boundary. Törnqvist et al. claim that adopting a volumetric approach "not only affects the magnitude but also the sign of [our] projections". Through our sensitivity analysis, exploring the elevation capital of inland migrating wetlands by only allowing wetland inland migration with no sediment accretion, we demonstrate that this argument is incorrect. Model runs with this extreme, hypothetical scenario still result in net gains of global coastal wetlands through inland migration (ED Fig. 2 in Schuerch et al. ${ }^{1}$ ), hence demonstrating that our predicted trends in wetland area would not change direction if sediment supply was considered volumetrically. 
Conceptually, the the A/S ratio (i.e. reduced vertical accretion rates for larger areas of wetlands) could be implemented into our model by dynamically adjusting the slope of the $\mathrm{SSC}_{\text {crit }}$-RSLR relationship (eq. 3 in Schuerch et al. $^{1}$ ) as a function of the time-dependent wetland area. However, restrictions on the availability of global near-shore suspended sediment volumes do not yet allow us to take this approach. Instead, we approximate the sediment availability of coastal wetlands with validated, state-of-the-art global SSC data (Globcolour data: http://www.globcolour.info/) ${ }^{1}$. We acknowledge that by using presentday SSC data for projections into the future, we do not account for potential reductions in global riverine sediment supply ${ }^{15}$, and potentially overestimate future global sediment availability (as discussed in Schuerch et al. ${ }^{1}$ ). However, our model shows that this effect is of lower importance than accounting for the inland migration potential of coastal wetlands ${ }^{1}$.

In conclusion, our modelling approach allows for an improved estimate of the response of global coastal wetlands to future environmental forcing, highlighting the policy-relevant importance of inland migration for their development and survival. Here, we show that our model is capable of reproducing regional trends and that the approach suggested by Törnqvist et al. does not apply for coastal wetland modelling, because it overemphasises the need for sedimentation within the wetland migration process. Our model provides crucial insights into the adaptation mechanisms of global coastal wetlands to SLR, particularly the wetland migration process, and gives a clear focus on the key processes and questions that future research should consider to better inform wetland futures and their sustainable management.

\section{Data and code availability}

All data referred to in this reply can be replicated using the publised computer code (open for noncommercial use (CC BY-NC-SA 4.0)), available from the GitLab repository 'global-coastal-wetland-model' (https://gitlab.com/mark.schuerch/global-coastal-wetland-model.git). Registration on GitLab is required to access the repository.

\section{Author contributions}

All authors discussed the content of this reply. M.S. wrote the first draft with input provided by all authors.

\section{Competing interests}

The authors declare no competing interest.

\section{References}

1 Schuerch, M. et al. Future response of global coastal wetlands to sea-level rise. Nature 561, 231234 (2018).

2 Day, J.W. et al. Restoration of the Mississippi Delta: Lessons from Hurricanes Katrina and Rita. Science 315, 1679-1684 (2007).

3 Coastal Protection and Restoration Authority of Louisiana. Louisiana's Comprehensive Master Plan for a Sustainable Coast (Coastal Protection and Restoration Authority of Louisiana, Baton Rouge, LA, 2017).

4 Jankowski, K.L., Törnqvist, T.E. \& Fernandes, A.M. Vulnerability of Louisiana's coastal wetlands to present-day rates of relative sea-level rise. Nature Communications 8, 14792 (2017).

5 Raabe, E.A. \& Stumpf, R.P. Expansion of Tidal Marsh in Response to Sea-Level Rise: Gulf Coast of Florida, USA. Estuaries and Coasts 39, 145-157 (2016).

6 Enwright, N.M., Griffith, K.T. \& Osland, M.J. Barriers to and opportunities for landward migration of coastal wetlands with sea-level rise. Frontiers in Ecology and the Environment 14, 307-316 (2016). 
7 Kirwan, M.L., Walters, D.C., Reay, W.G. \& Carr, J.A. Sea level driven marsh expansion in a coupled model of marsh erosion and migration. Geophysical Research Letters 43, 4366-4373.

8 Schieder, N.W., Walters, D.C. \& Kirwan, M.L. Massive Upland to Wetland Conversion Compensated for Historical Marsh Loss in Chesapeake Bay, USA. Estuaries and Coasts 41, 940951 (2017).

$9 \quad$ Kirwan, M.L. \& Gedan, K.B. Sea-level driven land conversion and the formation of ghost forests. Nature Climate Change 9, 450-457 (2019).

10 Feagin, R.A. et al. Salt marsh zonal migration and ecosystem service change in response to global sea level rise: a case study from an urban region. Ecology and Society 15, 14 (2010).

11 Dahl, T.E. \& Stedman, S.M. Status and trends of wetlands in the coastal watershedsof the Conterminous United States 2004 to 2009 (U.S. Department of the Interior; Fish and Wildlife Service, Washington, D.C., 2013).

12 Craft, C., Broome, S. \& Campbell, C. Fifteen Years of Vegetation and Soil Development after Brackish-Water Marsh Creation. Restoration Ecology 10, 248-258 (2002).

13 Cahoon, D.R., Lynch, J.C., Roman, C.T., Schmit, J.P. \& Skidds, D.E. Evaluating the Relationship Among Wetland Vertical Development, Elevation Capital, Sea-Level Rise, and Tidal Marsh Sustainability. Estuaries and Coasts 42, 1-15 (2019)

14 Muto, T. \& Steel, R.J. Principles of regression and transgression; the nature of the interplay between accommodation and sediment supply. Journal of Sedimentary Research 67, 994-1000 (1997).

15 Dunn, F.E. et al. Projections of declining fluvial sediment delivery to major deltas worldwide in response to climate change and anthropogenic stress. Environmental Research Letters 14, 084034 (2019). 